\title{
Suspected zoonotic transmission of rotavirus group A in Danish adults
}

\author{
Midgley, S. E.; Hjulsager, Charlotte Kristiane; Larsen, Lars Erik; Falkenhorst, G.; Böttiger, B.
}

\section{Published in:}

Epidemiology and Infection

Link to article, DOI:

10.1017/S0950268811001981

Publication date:

2012

Document Version

Publisher's PDF, also known as Version of record

Link back to DTU Orbit

Citation (APA):

Midgley, S. E., Hjulsager, C. K., Larsen, L. E., Falkenhorst, G., \& Böttiger, B. (2012). Suspected zoonotic transmission of rotavirus group A in Danish adults. Epidemiology and Infection, 140(6), 1013-1017. https://doi.org/10.1017/S0950268811001981

\section{General rights}

Copyright and moral rights for the publications made accessible in the public portal are retained by the authors and/or other copyright owners and it is a condition of accessing publications that users recognise and abide by the legal requirements associated with these rights.

- Users may download and print one copy of any publication from the public portal for the purpose of private study or research.

- You may not further distribute the material or use it for any profit-making activity or commercial gain

- You may freely distribute the URL identifying the publication in the public portal 


\title{
SHORT REPORT \\ Suspected zoonotic transmission of rotavirus group $A$ in Danish adults
}

\author{
S. E. MIDGLEY ${ }^{1}$, C. K. HJULSAGER ${ }^{2}$, L. E. LARSEN ${ }^{2}$, G. FALKENHORST ${ }^{3}$ \\ AND B. BÖTTIGER ${ }^{1 *}$ \\ ${ }^{1}$ Department of Virology, Statens Serum Institut, Copenhagen, Denmark \\ ${ }^{2}$ Division of Veterinary Diagnostics and Research, National Veterinary Institute, Technical University of \\ Denmark, Copenhagen, Denmark \\ ${ }^{3}$ Department of Epidemiology, Statens Serum Institut, Copenhagen, Denmark
}

(Accepted 31 August 2011; first published online 27 September 2011)

\section{SUMMARY}

Group A rotaviruses infect humans and a variety of animals. In July 2006 a rare rotavirus strain with G8P[14] specificity was identified in the stool samples of two adult patients with diarrheoa, who lived in the same geographical area in Denmark. Nucleotide sequences of the VP7, VP4, VP6, and NSP4 genes of the identified strains were identical. Phylogenetic analyses showed that both Danish G8P[14] strains clustered with rotaviruses of animal, mainly, bovine and caprine, origin. The high genetic relatedness to animal rotaviruses and the atypical epidemiological features suggest that these human G8P[14] strains were acquired through direct zoonotic transmission events.

Key words: Rotavirus, zoonoses.

Rotavirus is the main cause of acute gastroenteritis in children worldwide. Rotaviruses are also associated with gastroenteritis in animals, and can infect a broad range of animal species including dogs, cats, cattle, horses, and birds [1].

The rotavirus particle consists of a double-stranded RNA genome surrounded by a capsid. The genome consists of 11 segments, each coding for a separate protein. Two proteins, VP4 and VP7, are present on the surface of the virus, and their antigens are important for virus neutralization and protective immunity. Their corresponding genes define the $\mathrm{P}$ and $\mathrm{G}$ genotypes, respectively [1]. Recently, a classification system for rotaviruses based on sequence information from all 11 gene segments has been proposed [2].

\footnotetext{
* Author for correspondence: B. Böttiger, M.D., Department of Virology, Statens Serum Institut, Artillerivej 5, DK-2300 Copenhagen S, Denmark.

(Email: bbo@ssi.dk)
}

At present, 24 different $\mathrm{G}$ genotypes and $33 \mathrm{P}$ genotypes have been described [3]. In Europe, the most common rotavirus types in humans are G1-G4 and G9 mainly in combination with $\mathrm{P}[8]$ and $\mathrm{P}[4]$ [4].

Another capsid protein, VP6, defines the rotavirus group specificity and can according to the proposed classification system be divided into 11 different genotypes (I1-I11) [2]. NSP4 is a non-structural protein involved in the morphogenesis and pathogenesis of rotaviruses and also an enterotoxin that can induce diarrhoea by itself. To date, at least 11 distinct genotypes have been recognized (E1-E11) [2]. Due to the segmented nature of the rotavirus genome, co-infection with more than one strain, can lead to the emergence of new reassortant rotavirus variants.

Recently rotavirus vaccines have become available, and surveillance of circulating rotavirus types is therefore needed. As part of a European collaborative 
surveillance project, EuroRotaNet [4], we have characterized rotavirus strains from Denmark submitted to Statens Serum Institut from four diagnostic microbiological laboratories in different parts of the country. The G- and P-types were primarily determined by multiplex PCR following the algorithm and genotyping methods described on the EuroRotaNet website (http://www.eurorota.net/). In 2006 rotavirus genotypes were determined for 179 Danish patients. In $79 \%$ of the patients the most prevalent G-types, G1 and G9, were found most often in combination with $\mathrm{P}$ [8] as reported previously [4]. Of the less common rotavirus types, G8P[14] was identified in two patients. The patients were aged 28 and 35 years, respectively, and fell ill within 1 day of each other in July 2006. They were resident in the same part of Denmark, about $45 \mathrm{~km}$ apart. Both patients suffered from non-bloody diarrhoea, nausea, abdominal cramps, joint pains, headache, and weakness, and one of them also reported fever. Symptoms lasted for 10 and 15 days, respectively. The first patient reported contact with cows and goats in a petting zoo in the 5 days prior to onset of illness, as well as contact with the family cat and dog. The second patient reported contact with a dog and a parrot. Neither patient reported contact with another person with gastrointestinal symptoms or travel in the 5 days before illness. We could not establish whether the two patients had contact with each other.

To further characterize the virus detected in the samples from the two patients partial sequencing was performed for the following gene fragments: VP4 (length $596 \mathrm{bp}$ ), VP7 (length $855 \mathrm{bp),} \mathrm{VP6} \mathrm{(length}$ $293 \mathrm{bp}$ ) and NSP4 (length $494 \mathrm{bp}$ ). Sequences were aligned using the Simmonics sequence editor (http:// www.virus-evolution.org) and neighbour joining phylogenetic analysis was performed using MEGA4 after removal of the primer sequences. Since both samples were $100 \%$ identical in the four sequenced genome regions, only one of them, $06 \mathrm{H} 9151$, was used in the phylogenetic analysis, and was submitted to GenBank (accession nos. JN247736-JN247739).

In the phylogenetic analysis the most similar sequences from GenBank were included. Where

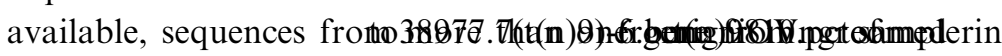

the same strain were included. Thus three samples, OVR762, Hu/BP1062/04 and Bo/BRV/68 were included in all four trees. VP6 and NSP4 sequences from Danish bovine rotavirus isolates from 2006 to 2007 were also included in the analysis (GenBank accession nos. JN248447-JN248460).
Phylogenetic analysis (Fig. 1) determined the genotype to be G8P[14]-I2-E2. The Rotavirus Classification Working Group [2] recommends that at least 500-bp-long fragments should be used for assigning a genotype. In this study we obtained VP4 and VP7 sequences longer than $500 \mathrm{bp}$, but the VP6 and NSP4 sequences are shorter, 293 and $496 \mathrm{bp}$, respectively.

In both the VP7 and VP4 phylogenetic analysis, our strains clustered together with animal rotavirus strains (bovine, ovine, porcine, guanaco, antelope). The sequences in GenBank with the highest nucleotide identity to our strain were the bovine strain KJ34-2 (FJ206048) and the caprine strain Cap455 (AY128709), with $98 \%$ and $96 \%$ homology to the VP7 and VP4 sequences, respectively. The only human rotaviruses with a high similarity were strains previously shown to be human-animal reassortant strains, PR/1300/04 and A64. PR/1300/04 has a VP7 gene of bovine origin in combination with a human VP4 gene [5] and strain A64 consists mainly of genes of bovine origin together with VP7 and VP3 genes of human origin. Rotaviruses of G8P[14] specificity have been reported in a few children in Europe [5-7] and Australia [8]. Other human strains of the G8 genotype, in combination with variety of P-types, have been reported from throughout the world [9]. Sequences from these reported human G8 strains in GenBank showed less than $86 \%$ homology to our G8 sequence. Human $\mathrm{P}[14]$ rotavirus strains, mainly in combinations with G6, have been described in detail [6]. These human $\mathrm{P}[14]$ sequences showed $<89 \%$ homology to our VP4 sequences. The ovine strain OVR762 has been shown to be very closely related to five human G6P[14] strains, characterized by wholegenome sequencing, suggesting a rather recent interspecies transmission from sheep to humans [6]. In our VP4 analysis three of these thoroughly characterized human G6P[14] isolates formed a cluster with other human $\mathrm{P}[14]$ viruses, whereas our isolates formed a branch together with OVR762. Furthermore, our strains had the same genome constellation as OVR762, including the G-type.

G8 was not found in any other Danish patient 

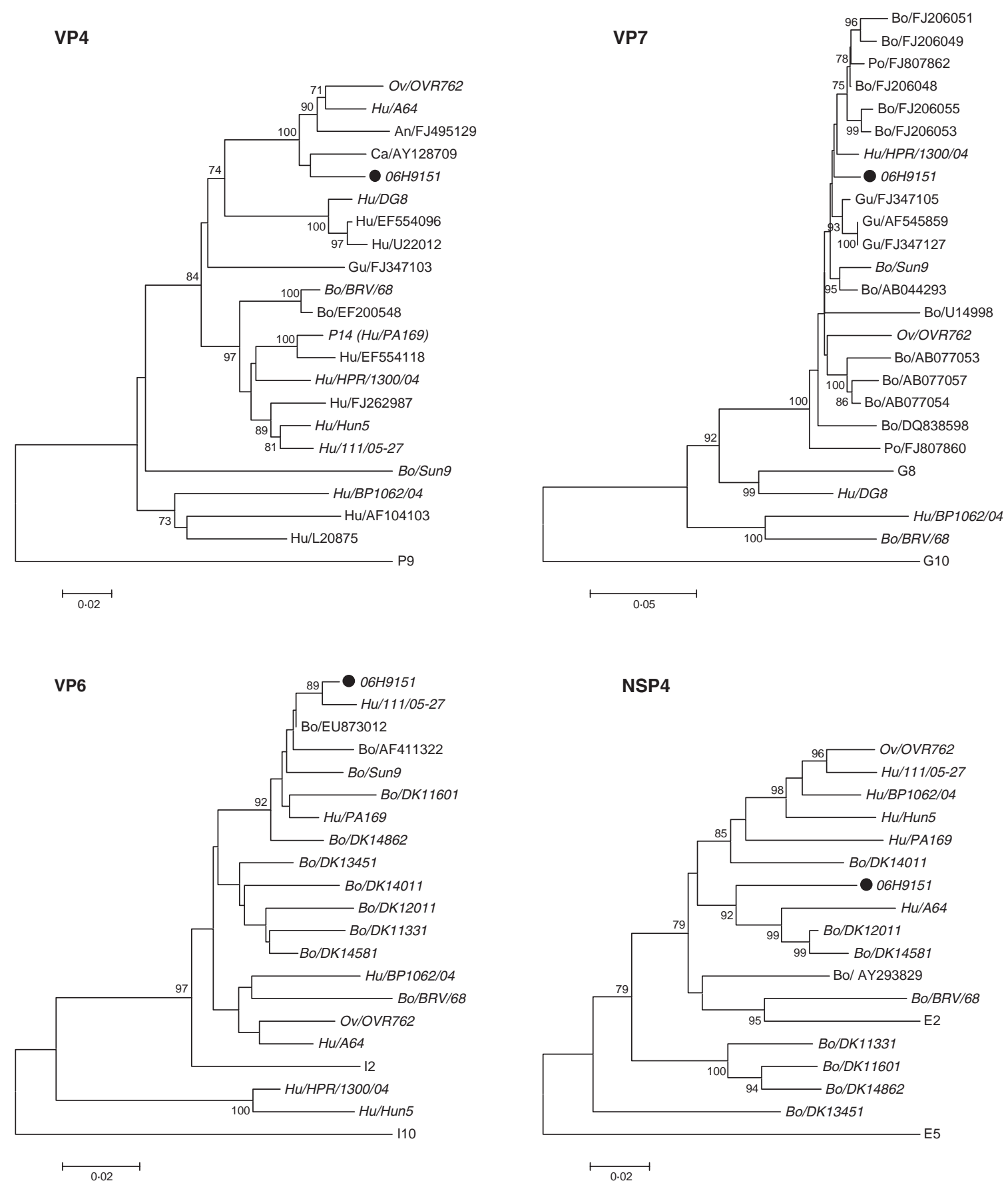

Fig. 1. Neighbour-joining phylogenetic trees were constructed using sequences from VP4, VP7, VP6, and NSP4 genes of rotaviruses from our sample $06 \mathrm{H} 9151$ and the most similar sequences from GenBank. The following sequence lengths of the four fragments were used: 596 bp (VP4), 855 bp (VP7), 293 bp (VP6) and 494 bp (NSP4). The nucleotide start positions of each fragment in relation to its corresponding fragment in the simian rotavirus strain, SA11, is as follows: 151 (VP4), 17 (VP7), 724 (VP6) and 34 (NSP4). The Jukes-Cantor algorithm was used with 100 bootstrap replications. The sequence names were constructed using the GenBank accession number with a prefix showing the species from which the virus had been isolated ( $\mathrm{Hu}$, human; Ov, ovine; An, antelope; $\mathrm{Ca}$, caprine; Gu, guanaco; Bo, bovine; Po, porcine). If an isolate is present in more than one of the trees the GenBank accession number has been replaced by the isolate name and it appears in italics. The isolate from this study is marked with a solid black symbol $(\bullet)$. Reference sequences included are identified by their type denomination; P for VP4, G for VP7, I for VP6, and E for NSP4. The following isolates have been used as reference sequences: P[14], PA169 (EF554129); P[9], HRII type 1 (D90260) (included as the closest outlier to root the tree); G8, B37 (J04334); G10, B223 (X57852) (included as the closest outlier to root the tree); I2, DRC86 (DQ005121); I10, ROTDIRRPTX (L11595) (included as the closest outlier to root the tree); E2, HST369/BR/1999 (DQ525190); E5, 160/01 (AF533535) (included as the closest outlier to root the tree). 
the G6P[14] genotype. As already mentioned these human strains have been shown to have a close overall genomic relatedness to ovine and antelope rotavirus strains [6]. The GenBank sequences with the highest nucleotide identity to our strain were the bovine strain Kv0426 (EU873012) and the human strain 111/05-27 (EF554141) with $98 \%$ homology to the VP6 sequence.

A similar pattern was seen in the NSP4 tree. Our isolate clustered together with animal rotaviruses and human strains which have been considered as reassortants or genetically closely related to ovine and antelope strains. The GenBank sequences with the highest nucleotide identity to our strain were the human strain A64 (D10772) and the buffalo strain 10733 (AY293829) with $92 \%$ and $91 \%$ homology to our strain, respectively.

In this study we have not sequenced the complete gene segments. However, the phylogenetic clustering of the reference strains we have used is consistent with what has been shown in another study including some of the same strains, and where the whole genome was determined [9].

The genotype constellation of our strain, G8P[14]I2-E2, is compatible with rotavirus strains of animal origin (sheep, goat, cattle), which made us suspect that a zoonotic transmission had occurred. However, we could not identify any G8 or P[14] rotaviruses in the samples typed from 18 Danish pigs and 30 cows. The bovine samples were collected in 2006 and 2007, from several different geographical locations, including the area where the two patients from this study were resident. We also tested 30 samples from goats but they were all rotavirus negative.

The G8P[14]-I2-E2 genome constellation has also been reported recently in Hungary, in a sample from a child (strain BP/1062/04) [7]. Phylogenetic comparison of the VP4, VP6, VP7 and NSP4 genes of $\mathrm{BP} / 1062 / 04$ and the strains reported in this study showed that these were not closely related in any of the gene fragments analysed. The NSP4 fragment was the only gene where the strains could be found in the same cluster. This suggests that there is no common origin for these strains, even though they show a high degree of similarity to strains of animal origin and share the same genome constellation.

Suspected transmission of rotaviruses from animals to humans, and vice versa, has been described in Slovenia and Hungary [10, 11]. Furthermore, wholegenome analysis of rotaviruses isolated from humans has identified strains where all 11 genes are of animal origin, from rabbit, cat and dog [12]. This strongly suggests the occurrence of zoonotic transmission of rotaviruses. The close relatedness of the four genes from our samples to strains of animal origin suggests a zoonotic transmission in our two patients also. Sequencing of the complete genes, or the complete genome, would clarify the genetic relatedness further.

It is interesting that a virus with identical sequences on four genome segments was detected in two different patients. The most plausible explanation for this is that they have had a common source of infection, even though the exact source could not be identified. These two patients lived in the same area, were both adults, and fell ill at the same time in July, which is outside the rotavirus season in Denmark. One of them reported contact with cattle and goats a few days before onset of illness. The atypical epidemiological information of the patients differs from the usual seasonal rotavirus outbreaks. This suggests an unusual source of infection and makes a zoonotic event plausible. This is further supported by the results from the phylogenetic analysis, which suggests that the most likely origin of the virus is an animal source. A reassortment event with human strains seems less likely as the infections occurred in the non-endemic season with a low level of other circulating human rotaviruses.

We therefore believe that this could be the first description of a direct zoonotic transmission of rotavirus infection in Denmark, most likely due to two separate transmission events from animals, in this case most likely cattle. No outbreaks or further circulation of this virus type have been seen subsequently. This supports the previously reported observation that non-reassortant viruses of zoonotic origin are unable to be easily transmitted in human populations [6].

\section{ACKNOWLEDGEMENTS}

This study was partly funded by EuroRotaNet.

This case-control study on risk factors for rotavirus infection in adults was approved by the Scientific Ethics Committee for Copenhagen and Frederiksberg, registration number (KF) 01260998.

\section{DECLARATION OF INTEREST}

None. 


\section{REFERENCES}

1. Estes MK, Kapikian AZ. Rotaviruses. In: Knipe DM, Howley PM, eds. Fields Virology, 5th edn. USA: Lippincott Williams \& Wilkins, 2007, pp. 1917-1974.

2. Matthijnssens $\mathbf{J}$, et al. Recommendations for the classification of group A rotaviruses using all 11 genomic RNA segments. Archives of Virology 2008; 153: 1621-1629.

3. Abe M, et al. Whole genome characterization of new bovine rotavirus G21P[29] and G24P[33] strains provides evidence for interspecies transmission. Journal of General Virology 2011; 92: 952-960.

4. Iturriza-Gómara M, et al. Rotavirus surveillance in Europe: web-enabled reporting and real-time analysis of genotyping and epidemiological data. Journal of Infectious Diseases 2009; 200 (Suppl. 1): S215-221.

5. Medici MC, et al. Molecular characterization of VP4, VP6 and VP7 genes of a rare G8P[14] rotavirus strain detected in an infant with gastroenteritis in Italy. Virus Research 2008; 137: 163-167.

6. Matthijnssens $\mathbf{J}$, et al. Are human $\mathrm{P}[14]$ rotavirus strains the result of interspecies transmissions from sheep or other ungulates that belong to the mammalian order Artiodactyla? Journal of Virology 2009; 83: 2917-2929.

7. Bányai K, et al. Whole genome sequencing and phylogenetic analysis of a zoonotic human G8P[14] rotavirus strain. Infection, Genetics and Evolution 2010; 10: 1140-1144.

8. Palombo EA, et al. Characterization of a European-like serotype G8 human rotavirus isolated in Australia. Journal of Medical Virology 2000; 60: 56-62.

9. Esona MD, et al. Genomic characterization of human rotavirus G8 strains from the African Rotavirus network: Relationship to animal rotaviruses. Journal of Medical Virology 2009; 81: 937-51.

10. Steyer A, et al. Human, porcine and bovine rotaviruses in Slovenia: evidence of interspecies transmission and genome reassortment. Journal of General Virology 2008; 89: 1690-1698.

11. Bányai K, et al. Genetic diversity and zoonotic potential of human rotavirus strains, 2003-2006, Hungary. Journal of Medical Virology 2009; 81: 362-370.

12. Martella V, et al. Zoonotic aspects of rotaviruses. Veterinary Microbiology 2010; 140: 246-255. 